in collected form (Columbus, O.: Ohio State University, Dept. of Physics, 1935, pp. 104, 1 dollar). W. F. G. Swann contributes an account of cosmic rays in which he explains his theory of particles producing secondaries frequently at first and less frequently as they lose energy in penetrating the earth's atmosphere. He also speculates on the origin of the energy of the charged particles. M. L. Pool contributes an article on the energies and products involved in nuclear disintegration and synthesis, which contains a number of extremely useful tables and data on these processes. H. L. Johnston summarises the uses of deuterium as a research tool in physics, chemistry and biology. E. O. Lawrence gives a historical survey of artificial radioactivity and an account of recent work in the California laboratory on this subject. G. Gamow contributes a short article on nuclear transformation and the origin of chemical elements which discusses the astrophysical aspect of nuclear reactions.

\section{Spanish Archæology and the University of Oxford}

As important addition to the provision for archæological research in the University of Oxford will be made by the election by Queen's College of a research student in archæology at some time in June next. The field of research will be Spain, or some part of Spain, and the period under investigation will lie between the earliest Neolithic Age and 200 B.c. The period of tenure will be two years and the stipend $£ 300$ per annum. In view of the importance of Spain as a centre of culture, especially in the develop. ment of art, in later palæolithic times, and of the desirability of a clearer understanding of its cultural relations in that and the succeeding mesolithic period, the restriction to the early neolithic period may appear open to comment; but no doubt it was held that these periods are at present sufficiently covered by those already concerned with the prehistoric archæo. logy of Europe generally, while development of the megalithic culture and the bronze and iron ages offer a no less fruitful and still to some extent uncultivated field to which attention may be directed to greater advantage in present conditions.

\section{Science and Human Welfare}

Followrng upon an informal meeting at which persons connected with some fifteen organisations interested in sociological and scientific problems were present, a Research Co-ordination Committee was formed to draw up plans for the co-ordination of scientific research as applied to human welfare. The Committee held its first meeting on January 30 at Morley College, London, and drafted a preliminary list of problems worthy of investigation and a list of organisations that are likely to have material bearing on those problems. As an example may be cited problems arising out of the housing question in connexion with the clearance of slums. Five aspects (architectural, engineering, financial, medical and socjological) have been put down for consideration, and steps are being taken to collect the necessary information. The offices of the Committee are at Hazlitt House, Southampton Buildings, W.C.2.

\section{Chemical Research in Czechoslovakia}

THE Collection of Czechoslovak Chemical Com. munications has just completed its seventh volume. This journal continues to record the investigations in pure chemistry carried out at the Universities of Prague and Brno. It is significant that no less than thirteen papers describing polarographic researches with the dropping mercury cathode appeared last year from the laboratory of Prof. J. Heyrovský. Prof. E. Votoček and his co-workers published ten papers dealing with various sugar derivatives and their behaviour with Grignard's reagents and other organic bodies. Another fruitful field of research has been the application of organic reagents for the detection and estimation of metals. This work is being carried out at Brno by Prof. Dubský and his fellow-investigators.

\section{An Active Group of Sunspots}

A RECENT group of sunspots, not remarkable for size, complexity or visible changes of structure, has proved of interest on account of its great activity when observed spectroscopically, especially in the hydrogen line $\mathrm{C}$ or $H \alpha$ of the solar spectrum. The group consisted of two spots of regular outline, $10^{\circ}$ apart in solar longitude, accompanied by two or three wide clusters of small spots, making in all a stream extending over $20^{\circ}$ of longitude. The position of the centre of the stream was: long. $164^{\circ}$; lat. $27^{\circ} \mathrm{S}$.; central meridian passage February $14 \cdot 0$, when the spots passed about $20^{\circ}$ of latitude south of the centre of the sun's disk. The area of the stream averaged about 800 millionths of the sun's hemisphere or 930 million square miles. Between February 7 and 14 inclusive, the spots were examined as often as possible with the Hale spectrohelioscope at the Royal Observatory, Greenwich, for a total duration of 16 hours on six days, usually before $13^{\text {h }}$ U.T. During these hours of watching, equivalent to about one-ninth of the total duration of the epoch, eight bright eruptions of hydrogen were observed, so that a considerable number of eruptions is indicated by this sampling as having taken place in connexion with the spots.

Most of the eruptions were of minor importance, but on February 14 one of appreciable extent, and involving large radial velocities of accompanying dark clouds of hydrogen, was fortunately observed in its entirety. This eruption, which occurred within a few degrees of longitude from the central meridian, began within a minute or two of $12^{\mathrm{h}} 39^{\mathrm{m}}$ and lasted until $13^{\mathrm{h}} 27^{\mathrm{m}}$ U.T. Besides the streaks of bright emission, which at their maximum intensity were about equal to that of the continuous spectrum adjacent to $H \alpha$, a dense cloud of relatively dark hydrogen was moving outwards from the sun with a maximum observed velocity of $210 \mathrm{~km}$./sec. Within ten minutes, other dark patches or filaments were visible with velocities of recession, showing that the ejected hydrogen was to a large extent falling back towards the sun, and by $13^{\mathrm{h}} 03^{\mathrm{m}}$ when the outward motions had ceased, the measured inward velocities were of the order of 
$115 \mathrm{~km}$. $/$ sec. By $13^{\mathrm{h}} 14^{\mathrm{m}}$ these latter velocities had increased to $+190 \mathrm{~km}$. $/ \mathrm{sec}$, and at $13^{\mathrm{h}} 22^{\mathrm{m}}$, when the phenomenon was abruptly ceasing, a faint patch gave a measured velocity of $+220 \mathrm{~km}$. $/ \mathrm{sec}$. At the time of writing (February 15), further observations of the group were impossible owing to fog and cloud. These observations, which illustrate a typical bright $H \alpha$ eruption (probably also visible in the $\mathrm{H}$ and $\mathrm{K}$ lines of ionised calcium), are strongly suggestive of the conditions, worked out in 1926 by Prof. E. A. Milne in his theory of the solar chromosphere, for the ejection of high-speed particles from the sun. Since the active area on February 14 was favourably, though not ideally, placed on the disk for corpuscular streams to reach the earth, reports on disturbances of the earth's magnetic field and on radio reception will be of special interest.

\section{Announcements}

Sir Wrlliam Bragg, president of the Royal Society, will open the Very Low Temperatures Exhibition in the Lecture Theatre of the Science Museum, South Kensington, at 3 p.m. on Wednesday, March 4. The chair will be taken by Sir Henry Lyons.

THE Faraday Society will hold a general discussion on "Disperse Systems in Gases; Dust, Smoke and Fog" at the University of Leeds on April 20-22. The discussion will be divided in two parts : Part I, General, to be introduced by Prof. R. Whytlaw. Gray, and Part II, Special, to be opened by Dr. R. Lessing. A number of distinguished foreign visitors will be present. Further information can be obtained from the Secretary, Faraday Society, 13 South Square, Gray's Inn, London, W.C.1.

Current Science, published in Bangalore, announces the appointment of the quinquennial reviewing committee of the Indian Institute of Science. The personnel of the committee is as follows: Sir James Irvine (Chairman), Dr. A. H. Mackenzie, Dr. S. S. Bhatnagar and Mr. F. F. C. Edmunds (Secretary). Sir James Irvine is Vice-Chancellor and Principal of the University of St. Andrews. Dr. Mackenzie is Pro-Vice-Chancellor of the Osmania University, Hyderabad, Decean. Dr. Bhatnagar is university professor of physical chemistry and director of chemical laboratories, University of the Punjab. Mr. Edmunds Inspector of Schools, Coorg and Bangalore, was the secretary of the last reviewing committee, constituted in 1930 .

Ax the annual general meeting of the Quekett Microscopical Club held on February 11 the following officers were elected: President, C. D. Soar; Vice-Presidents, J. Ramsbottom, E. A. Robins, J. T. Holder, Dr. C. Tierney; Hon. Treasurer, C. H. Bestow; Hon. Secretary, W. S. Warton; Hon. Reporter, A. Morley Jones; Hon. Librarian, W. E. Stone; Hon. Curator, C. J. Sidwell ; Hon. Editor, W. P. Sollis ; New Members of the Committee, H. G. Brown, C. H. Caffyn, H. C. Payne and P. K. Sartory.
AT the annual general meeting of the Royal Astronomical Society held on February 14, the following officers were elected: President, J. H. Reynolds; Vice-Presidents, Prof. S. Chapman, Dr. H. Knox-Shaw, Prof. E. A. Milne and Prof. H. C. Plummer ; Treasurer, Sir Frank Dyson; Secretaries, W. M. H. Greaves and Dr. W. M. Smart; Foreign Secretary, Sir Arthur Eddington; Members of Council, C. R. Davidson, Dr. H. Dingle, Prof. R. H. Fowler, Dr. H. Spencer Jones, Dr. W. J. S. Lockyer, Prof. W. H. McCrea, P. J. Melotte, Rev. T. E. R. Phillips, Prof. H. H. Plaskett, Dr. R. O. Redman, Dr. W. H. Steavenson and Dr. R. H. Stoneley.

THE centenary of the foundation of the National University of Athens by King Otho will be celebrated on May 15, 1937. An International Congress of Archæology will be held at the same time, on the occasion of the centenary of the foundation of the Greek Society of Archæology.

Prof. Leo Frobenius, director of the Research Institute for Cultural Morphology at Frankforton-Main, has been awarded the Bernhard-Hagen Medal by the Frankfort Society for Anthropology, Ethnology and Primeval History.

THe first international meeting on fever therapy will be held in New York City in September 1936. The use of fever induced by physical and other agencies as a therapeutic procedure has received universal attention in the past few years. The conference will aim at collecting and crystallising available data in this field. Therapeutic, physiological and pathologica] phases of fever will be discussed. It is planned to translate abstracts of all the papers into French, English and German. Further information concerning the conference may be obtained from the Secretary, Dr. William Bierman, 471 Park Avenue, New York City, U.S.A.

Applications are invited for the following appointments, on or before the dates mentioned:

A junior investigator to the British Non-Ferrous Metals Research Association, Regnart Buildings, Euston Street, N.W.1-The Secretary (Feb. 21).

Assistants (Grade II) at the Royal Aircraft Establishment, South Farnborough, Hants-The Chief Superintendent (Ref. A. 922), Royal Aircraft Establishment, South Farnborough, Hants (Feb. 28).

A head of the Department of Pure and Applied Physics in the College of Technology, ManchesterThe Registrar (March 2).

A professor of pure mathematics in the Egyptian University-The Dean of the Faculty of Science, Egyptian University, Abbassia, Cairo (March 15).

A member of staff of the Radio Research Board of the Council for Scientific and Industrial Research, Australia-F. L. McDougall, Australia House, Strand, London, W.C.2 (March 23).

A professor of engineering in the University of Melbourne-The Secretary, Universities Bureau, 88a, Gower Street, London, W.C.1 (June 15). 